\title{
OCCURENCE AND ANTIBIOGRAM OF SALMONELLA SPP. IN RAW AND FERMENTED MILK IN ZARIA AND ENVIRONS
}

\author{
Z. Tamba ${ }^{1}$, M. Bello ${ }^{2}$ and M. A. Raji ${ }^{3}$ \\ ${ }^{1}$ Department of Veterinary Public Health and Preventive Medicine, ${ }^{2}$ Department of Veterinary Microbiology, \\ Ahmadu Bello University, Zaria, Nigeria; ${ }^{3}$ Department Veterinary Microbiology, Faculty of Veterinary \\ Medicine, University of Ilorin, Kwara State, Nigeria
}

\begin{abstract}
Salmonellosis is an important food-borne disease affecting both humans and animals. The aim of this study was to determine the occurrence and antibiogram of Salmonella species from raw and fermented milk. The results showed that out of the 350 milk samples examined $14(4.0 \%)$ were positive for salmonella. The prevalence of Salmonella is higher in raw milk $(4.6 \%)$ than in fermented milk $(3.4 \%)$ with no statistical difference $(\mathrm{P}>0.05)$ between them. The prevalence of both raw $(75.0 \%)$ and fermented milk $(83.33 \%)$ is significantly higher $(\mathrm{P}<0.05)$ in SabonGari LGA than in Giwa LGA with $25.0 \%$ and $16.67 \%$ respectively. No salmonella was isolated from the all the 50 raw and 78 fermented milk examined from Zaria LGA. The antibiotic susceptibility test showed that ciprofloxacin and gentamicin were $100 \%$ susceptible, while chloramphenicol, kanamycin, nalidixic acid showed 93\% susceptible each. Others are streptomycin and tetracycline (64.3\%), amoxicillin (21.4\%), ampicillin and erythromycin (14.3\%) and lincomycin (0\%). This connotes that all the Salmonella isolates were $100 \%$ resistance to lincomycin, $85.7 \%$ to erythromycin, $85.7 \%$ to ampicillin and $78.6 \%$ to amoxicillin. The antibiotic resistance pattern of 14 Salmonella isolates from raw and fermented milk showed 9 different resistance patterns of the 11 antimicrobial agents used. The Minimum Inhibitory Concentration (MIC) test showed that only 1(7.1\%) of the isolate was sensitive to Amoxicillin with $<0.12$ while the remaining $9(98.9 \%)$ were resistant to the two antibiotics used (AML and E) with >256.
\end{abstract}

Keywords: Antibiogram, Salmonella species, milk, minimum inhibitory concentration (MIC), Zaria, Nigeria

\section{INTRODUCTION}

Milk is a fresh, clean and normal mammary secretion obtained by milking of one or more dairy animals for nourishment of their young (Rani and Maheshwari, 2012). In dairy animals, cow milk is the most consumed milk worldwide and serves as good source of animal proteins, fats, vitamins and minerals to the human body (Muehlhoff et al., 2013). Food and Agricultural Organization (FAO) of the United Nations estimated that $85 \%$ of all milk world-wide was produced from cows (Gerosa and Skoet, 2013). Despite rich in nutrients, fresh milk and its fermented products constitute a good medium for the multiplication of various bacteria, and hence serve as a medium for the transmission of milk borne diseases mostly salmonellosis, brucellosis, tuberculosis, shigellosis and staphylococcosis (Gerosa and Skoet, 2013).

Pathogenic bacteria in raw milk have been a major factor for public health concern. The main sources of contamination are the dairy cattle handlers and dairy equipment (Zeinhom and Latef, 2014). Consumption of raw milk is considered to be the main cause of several outbreaks of Salmonella spp., Listeria monocytogenes and Escherichia coli O157:H7 (Grant et al., 1995) and posed the greatest human health problems in various countries (Lejeune and Rajala-Schultz, 2009). However, raw cow milk form the basis for most commonly sold local milk products in Nigeria. Some milk products in Nigeria include locally fermented skimmed milk known as "Nono", full creamed milk, "Kindirmo" local butter, "Man Shanu" and cheese, "Wara". Salmonella is a Gram negative bacterium, rod shaped, aerobic or facultative anaerobic, belonging to the family Enterobacteriaceae. It is a major pathogenic bacteria' inhabiting the intestinal tract of humans and animals (Holt et al., 1994). Salmonella spp are important sources of bacterial contamination of the environment and the food chain (Ponce et al., 2008), and are the leading causes of acute gastroenteritis in several countries (Soltan et al., 2009). Several studies in Nigeria and other parts of the world have documented the occurrence and prevalence of Salmonella in foods and milk in particular. For instance Karshima et al. (2013) had a prevalence of $6.4 \%$ from raw milk and $0.8 \%$ from fermented milk. Olatunji et al. (2012), also had a prevalence of $8.7 \%$ from raw milk.

*Corresponding e-mail address: salehzee1@gmail.com 


\section{Z. Tamba and others}

In Africa, Nyenje and Ndip (2013) in their study also recorded 43\% Salmonella from farms in raw milk and in the United States, Mead et al. (1999) documented different food borne pathogens of which Salmonella caused $31 \%$ of food related deaths, followed by Listera with 28\%, Campylobacter 5\% and Escherichia coli 3\%. This study is therefore, aimed at isolating and identifying Salmonella species from raw and locally fermented milk ("Nono") in Zaria, Nigeria.

\section{MATERIALS AND METHODS}

\section{Sample collection}

The study was carried out in Zaria, Kaduna State which is located within latitudes $11^{\circ} 07^{\prime}, 11^{0} 12^{\prime} \mathrm{N}$ and longitudes $07^{0} 41^{\prime} \mathrm{E}$, in the Northern region of Nigeria. A total of 350 samples were collected from 3 local Government areas (LGA) of Zaria and Environs (174 raw and 176 fermented milk samples) namely Giwa, Sabon-Gari, and Zaria. Herds of cattle were visited during milking time, where $10 \mathrm{ml}$ of raw milk samples were collected directly from milking cows using convenient sampling technique and placed into sterile sample bottles. Fermented milk (nono) samples were collected from 10 Fulani women at different retail points in the same locations into the sterile sample bottles. All the samples collected were placed on ice and transported to the Bacterial Zoonoses Laboratory, Faculty of Veterinary Medicine, Ahmadu Bello University, Zaria for analysis.

\section{Identification of the Salmonella spp}

Bacterial isolation, identification and biochemical tests (indole, methyl-red, Voges-Proskauer, citrate (IMViC), motility and triple sugar iron, TSI) were carried out using standard procedures described elsewhere (Cheesbrough, 2002). Pure cultures obtained from nutrient agar slants were subjected to biochemical tests. All the isolates were characterized using indole, methyl-red, Voges-Proskauer, citrate, motility, $\mathrm{H}_{2} \mathrm{~S}$, sugar fermentation tests as described by Quinn et al. (2002). The isolates were further characterized using Microbact 12E (Oxoid, Basingstoke, England).

\section{Sensitivity to antimicrobials}

The susceptibility of all the isolates were tested to the following antimicrobials such as chloramphenicol $(30 \mu \mathrm{g})$, ciprofloxacin $(5 \mu \mathrm{g})$, kanamycin $(30 \mu \mathrm{g})$, nalidixic acid $(30 \mu \mathrm{g})$ gentamicin $(10 \mu \mathrm{g})$, lincomycin $(10 \mu \mathrm{g})$, tetracycline $(10 \mu \mathrm{g})$, ampicillin $(10 \mu \mathrm{g})$, amoxicillin $(10 \mu \mathrm{g})$, streptomycin $(10 \mu \mathrm{g})$ and erythromycin $(15 \mu \mathrm{g}) \mathrm{using}$ the disk diffusion method described by CLSI (2011). Two colonies of the overnight culture were inoculated into $5 \mathrm{ml}$ tryptone soya broth (Oxoid, UK) and incubated at $37^{\circ} \mathrm{C}$ until the turbidity approximated 0.5 Mac Farmland's standard was obtained (CLSI, 2011). Mueller-Hinton agar plates were prepared and used according to manufactures instruction's sterile swabs were dipped into the broth culture with the excess broth drained by pressing on the inner side of the tube and used to streak the Mueller-Hinton agar until the entire surface was streaked. The plates were allowed to dry at room temperature for $10 \mathrm{~min}$ and the antimicrobial disc dispensed on the plates using the multiple disc dispenser (Oxoid, UK). The petridishes were then inverted and incubated at $37^{\circ} \mathrm{C}$ for $18 \mathrm{hrs}$, after which the zones of inhibition were measured to the nearest millimetre and interpreted based on interpretation of zone diameter of test culture provided by CLSI (2011).

\section{Determination of Minimum Inhibitory Concentration (MIC)}

Minimum inhibitory concentration (MIC) of erythromycin and amoxycillin against the 10 isolates was carried out at the National Food Institute Kemitovet, Technical University of Denmark, Denmark according to recommendations of CLSI (2011).

\section{Statistical analysis}

The occurrence of Salmonella species in raw and fermented milk were calculated using simple percentages and Chi square to test for association and values of $\mathrm{P}<0.05$ was considered statistically significant. The results were analysed using Statistical Package for Social Sciences (SPSS 20.0).

\section{RESULTS AND DISCUSSION}

The results showed that prevalence of Salmonella is higher in raw milk (4.6\%) than in fermented milk (3.4\%) with no statistical difference $(\mathrm{P}>0.05)$ between them (Table 1).The prevalence of both raw $(75.0 \%)$ and 
fermented milk $(83.33 \%)$ is significantly higher $(\mathrm{P}<0.05)$ in Sabon Gari LGA than in Giwa LGA with $25.0 \%$ and $16.67 \%$ respectively and no Salmonella was isolated from the all the 50 raw and 78 fermented milk examined from Zaria LGA.

The antibiotic susceptibility test showed that ciprofloxacin and gentamicin were $100 \%$ susceptible, while chloramphenicol, kanamycin, nalidixic acid showed 93\% susceptible each. Others are streptomycin and tetracycline, 64.3\%, amoxicillin (21.4\%), ampicillin and erythromycin (14.3\%) and lincomycin (0\%) (Table 2). This connotes that all the isolates were $100 \%$ resistance to lincomycin, $85.71 \%$ to erythromycin, $85.71 \%$ to ampicillin and $78.57 \%$ to amoxicillin (Table 2).

Table 1. Prevalence of Salmonella spp from raw and fermented milk based on LGA

\begin{tabular}{ccccc}
\hline \multirow{2}{*}{ LGA } & \multicolumn{2}{c}{ Raw milk } & \multicolumn{2}{c}{ Fermented milk } \\
\cline { 2 - 5 } & No. of samples examined & No. (\%) of Salmonella & No. of samples examined & No. (\%) of Salmonella \\
\hline S/Gari & 74 & $6(75.0)$ & 68 & $5(83.33)$ \\
Zaria & 50 & $0(0.0)$ & 78 & $0(0.00)$ \\
Giwa & 50 & $2(25.0)$ & 30 & $1(16.67)$ \\
\hline Total & 174 & $8(4.6)$ & 176 & $6(3.4)$ \\
\hline
\end{tabular}

Table 2. Susceptibility of Salmonella isolates to antimicrobial agents from raw and fermented milk samples

\begin{tabular}{clcc}
\hline S/No & Antimicrobial & No. of Salmonella susceptible & \% of Salmonella susceptible \\
\hline 1 & Chloramphenicol & 13 & 93.0 \\
2 & Ciprofloxacin & 14 & 100.0 \\
3 & Kanamycin & 13 & 93.0 \\
4 & Nalidixic Acid & 13 & 93.0 \\
5 & Gentamicin & 14 & 100.0 \\
6 & Ampicillin & 2 & 14.3 \\
7 & Amoxicillin & 3 & 21.4 \\
8 & Streptomycin & 9 & 64.3 \\
9 & Lincomycin & 0 & 0.0 \\
10 & Erythromycin & 2 & 14.3 \\
11 & Tetracycline & 9 & 64.3 \\
\hline
\end{tabular}

Table 3. Minimum inhibitory concentration evaluation on Salmonella species

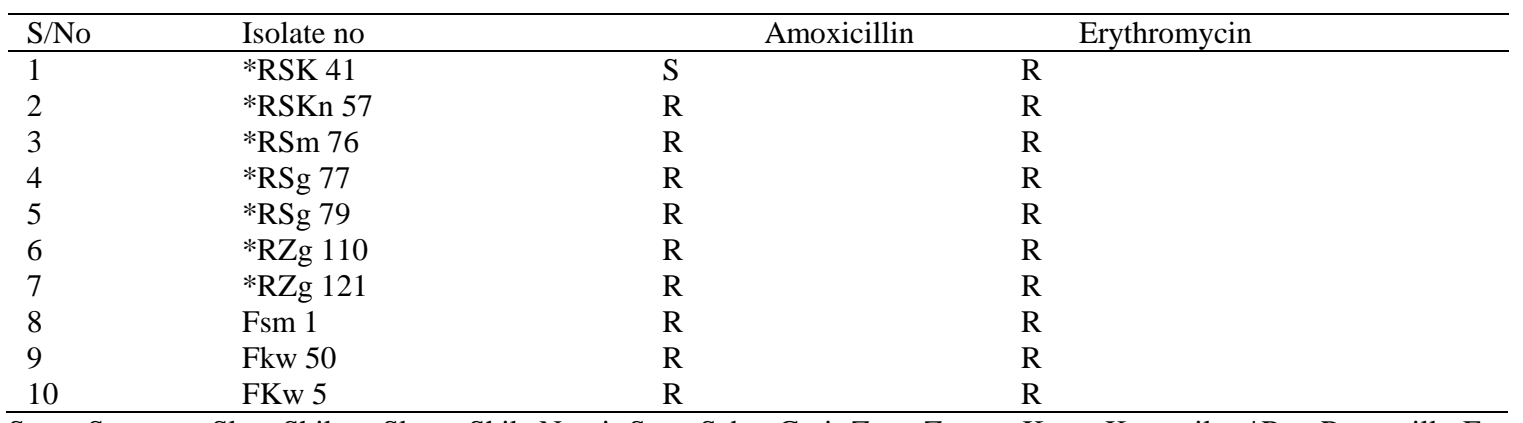

Sm = Samaru, Sk = Shika, Skn = ShikaNapri, Sg $=$ SabonGari, $\mathrm{Zg}=$ Zango, Kw $=$ Kwangila, $* \mathrm{R}=\mathrm{Raw}$ milk, $\mathrm{F}=$ Fermented milk; $\mathrm{S}=$ sensitive, $\mathrm{R}=$ resistance, $>256$ = resistant, $<256=$ sensitive

The Minimum Inhibitory Concentration (MIC) test showed that only 1(7.1\%) of the isolate was sensitive to 


\section{Z. Tamba and others}

amoxicillin with $<0.12$ while the remaining $9(98.9 \%)$ were resistant to the two antibiotics used (AML and E) with $>256$ (Table 3 ).

This study established the presence of Salmonella arizonae which are members of sub-species IIIa with overall prevalence of 4.0. Raw milk had $4.6 \%$ prevalence while fermented milk had $3.4 \%$ prevalence. The difference in prevalence between raw and fermented milk could be due to low $\mathrm{p}^{\mathrm{H}}$ and effect of fermentation in fermented milk because fermented milk is not a suitable environment for the majority of spoilage bacteria. Karshima et al. (2013) also had a higher prevalence of $6.4 \%$ from raw milk and $0.8 \%$ for fermented milk. Mhone et al. (2012) carried out a study in Zimbabwe from selected farms on raw and processed cow milk and out of all the samples collected, 0\% Salmonella spp. was reported. This result could be due to good management practices or small sample size or method of isolation used in their studies.

The 4\% prevalence established in this work is of public health importance, since the presence of one Salmonella species can lead to recall of food items from the market following the WHO standard (Codex Alimentarius Commission). Moreso, the reason for this high prevalence of Salmonella spp. in Sabon Gari LGA is probably due to the poor sanitary conditions of the milkers' hands, clothings and it could also be due to the presence of flies in the environment where the milk samples were collected, another probable reason could be the addition of baoba seeds, river or stream water, ice block to the milk so as to increase the quantity of the milk.

The antibiotic susceptibility test showed that isolates in raw and fermented milk are resistant to commonly used antibiotics and there was also resistance to multiple antimicrobials, including lincomycin, ampicillin, erythromycin, amoxicillin and tetracycline and showed sensitivity that is $(0 \%)$ resistance to gentamicin and ciprofloxacin. The probable reason of multidrug resistance with $100 \%$ resistance on lincomycin, erythromycin, ampicillin and amoxicillin may be due to the indiscriminate use of antibiotics by farmers and the vets in treating certain diseases of their animals. This finding is similar to that described by Chen et al. (2004).

Based on the minimum inhibitory concentration evaluation, amoxicillin and erythromycin strips were used. Only 1 Salmonella isolate had 0.12 zone of inhibition to amoxicillin strips while 9 isolates had zones of inhibition > 256 on both antibiotic used. This could be due th the presence of resistance gene but does not necessarily lead to treatment failure, because the level of expression may be too low. More so, the B-lactams showed high resistance while the floroquinolones and aminoglucoside shows $0 \%$ resistance, this agrees with the work of Tafida et al. (2013) who also carried out antibiotics study on Salmonella isolates in retail beef and related meat product in Zaria, reported low prevalence of resistance to fluoroquinolones (ciprofloxacin) and aminoglycoside (Gentamicin) but high prevalence of resistance to macrolide (erythromycin) and amantadine (amoxicillin). Also, antibiotic resistance shown by $90 \%$ of the Salmonella arizonae indicates indiscriminate use of antibiotics by both the veterinarians and the animal owners and calls for corrective measures.

In conclusion, this research has established the presence of Salmonella species with an overall prevalence of $4.0 \%$ in the milk samples, with raw milk recording $4.6 \%$ prevalence and locally fermented milk (Nono) recording 3.4\% prevalence in Zaria and environs. The results are not in agreement with the Codex Alimentarius Commission of the World Health Organization (WHO) which states "that milk for human consumption must be free of Salmonella". This study therefore recommended that milker's should practice personal hygiene by wearing clean clothing and washing their hands regularly with soap and water before milking the animals. There should be public health education to the fulani herds men on the need to practice personal hygiene by washing their hands regularly with soap and water before milking the animals and to wear clean clothing and also to keep the environment where the animals are kept clean.

\section{ACKNOWLEDGEMENTS}

The authors are grateful to Mal Tukur Mohammed for his assistance in linking me up with different herds men from where raw milk samples were collected. Authors also appreciate Prof. J. K. P. Kwaga for his immense contribution and guidance throughout the research and also the laboratory staff of veterinary public health and preventive medicine for their guidance and assistance.

\section{REFERENCES}

1. Cheesbrough M (2002). Medical laboratory manual for tropical countries. Cambridge University Press, $2^{\text {nd }}$ edn. 
2. Chen S, Zhao S, White DG, Schroeder CM, Lu R,Yang H, McDermott PF, Ayers S and Meng J (2004). Characterization of multiple-antimicrobial-resistant salmonella serovars isolated from retail meats. Applied and Environmental Microbiology 70: 1-7.

3. Clinical Laboratory Standards Institute (CLSI) (2011). Performance standards for antimicrobial susceptibility testing.Sixth informational supplement. CLSI document M100-516. CSLI 940 west valley road, suite 140, Wayne, Pennsylvania 19087-1898, USA, ISBN 1-56238-5887.

4. Gerosa S and Skoet J (2013). "Milk availability"-trends in production and demand and medium-term outlook in: milk and dairy products in human nutrition, Food and Agricultural Organization, Rome. Open Journal of Pediatrics 5: 11-40.

5. Grant IR, Ball HJ and Rowe MT (1995). Inactivation of M. tuberculosis in cow milk at pasteurization temperature. In proceedings of the fourth internal collegiums on paratuberculosis, St. John's College Cambridge, pp. 313-319.

6. Holt JG, Krieg NR, Sneath PHA and Williams ST (1994). Salmonella In: Berger's manual of determinative bacteriology, 9th edition. Williams and Wilkins Baltimore, pp. 787.

7. Karshima NS, Pam VA, Bata SI, Dung PA and Paman ND (2013). Isolation of Salmonella species from milk and locally processed milk products traded for human consumption and associated risk factors in Kanam, Plateau State, Nigeria. Journal of Animal Production Advances 3: 69-74.

8. Khandaghi J, Razavilar V and Barzgari A (2010). Isolation of Escherichia coli O157:H7 in Manure fertilizer farms and raw vegetables grown on it, in Tabriz in Iran. African Journal of Microbiology Research 4: 891-895.

9. Lejeune JT and Rajala-Schultz PJ (2009). Unpasteurized milk: a continued public health threat. Journal of Clinical Infectious Diseases 48: 93-100.

10. Mead PS, Slutsker L, Dietz V, McCaig LF, Bresee JS, Shapiro C, Gtiffin PM and Tauxe RV (1999). Food related illness and death in the United States. Journal of Emerging Infectious Disease 5: 607-625.

11. Mhone TA, Matope G and Saidi PT (2012). Detection of Salmonella spp., Candida albicans, Aspergillus spp., and antimicrobial residues in raw and processed cow milk from selected small-holder farms of Zimbabwe. Veterinary Medicine International doi:10.1155/2012/301902.

12. Muehlhoff E, Bennett A and Mc Mahon D (2013). Milk and dairying products in human nutrition, Published by FAO Rome, 41-74.

13. Nyenje ME and Ndip RN (2013). Review on the challenges of food-borne pathogens and antimicrobial chemotherapy: A global perspective. African Journal of Microbiology Research 7: 1158-1172.

14. Olatunji EA, Jubril AE, Okpu EO, Olafadehan OA, Ijah UJ and Njidda AA (2012). Bacterial assessment and quality analysis of raw milk sold in gwagwalada area council of the Federal Capital Territory (FCT) Abuja, Nigeria. Journal of Food Science and Quality Management 7: 1-4.

15. Oxoid Basingstoke-UK (2005). Microbact ${ }^{\mathrm{Tm}}$ Gram-negative identification system. Oxoid Limited, Basingstoke, pp. 4-7.

16. Oxoid Basingstoke-UK (2008). Antimicrobial susceptibility testing. M.I.C. Evaluation guide. Oxoid limited, pp. 47.

17. Ponce E, Khan AA, Cheng CM, Summage-West C and Cerniglia CE (2008). Prevalence and characterization of Salmonella enteric serovarWeltevreden from imported seafood. Journal of Food Microbiology 25: 29-35.

18. Quinn PJ, Markey BK, Carter ME, Donnelly WJC, Leonard FC (2002). Veterinary Microbiology and Microbial Disease. Oxford: Blackwell Science.

19. Rani B and Maheshwari R (2012). Biochemical and microbiological aspects of milk: A review. Bulletin of Environment, Pharmacology and Life Sciences 1: 57-63

20. Soltan M, Daalal MM, Taremi L, Gachkar S, Moderresi M, Sanaei R, Bakhtiari MK, Shaarifi Y and Zali MR (2009). Characterization of antibiotic resistant patterns of Salmonella serotypes isolated from beef and chicken samples in Tehran. Jundishapur Journal of Microbiology 2: 124-131.

21. Tafida SY, Kabir J, Kwaga JKP, Bello M, Umoh VJ, Yakubu SE, Nok AJ and Hendriksen R (2013). Occurrence of Salmonella in retail beef and related meat products in Zaria, Nigeria. Journal of Food Control 32: 119-124.

22. Zeinhom MA and Abdel Latef GK (2014). Public health risk of some milk borne pathogens. Journal of Basic and Applied Sciences 3: 209-215. 